\title{
Enhanced freedom from prosthesis-patient mismatch with transcatheter aortic valve replacement: More to aortic regurgitation than meets the eye?
}

\author{
Maria Rodriguez, MD, and Marc Ruel, MD, MPH
}

\author{
From the Division of Cardiac Surgery, University of Ottawa Heart Institute, Ottawa, Ontario, Canada. \\ Disclosures: Authors have nothing to disclose with regard to commercial support. \\ Received for publication Nov 20, 2015; accepted for publication Nov 25, 2015; available ahead of print Jan 15, \\ 2016 . \\ Address for reprints: Marc Ruel, MD, MPH, Division of Cardiac Surgery, University of Ottawa Heart Institute, 40 \\ Ruskin St, Suite 3403, Ottawa, ON, Canada K1Y 4W7 (E-mail: mruel@ottawaheart.ca). \\ J Thorac Cardiovasc Surg 2016;151:1024-5 \\ $0022-5223 / \$ 36.00$ \\ Copyright (c) 2016 by The American Association for Thoracic Surgery \\ http://dx.doi.org/10.1016/j.jtcvs.2015.11.050
}

Prosthesis-patient mismatch (PPM) is one of the less well understood "complications" of aortic valve replacement, because its manifestations are controversial and may be confounded by a wide range of baseline patient characteristics and operative variables. PPM occurs in $20 \%$ to $70 \%$ of surgical aortic valve replacement (SAVR) procedures ${ }^{1}$ and has been associated with decreased long-term survival and freedom from heart failure, particularly in patients with left ventricular (LV) dysfunction or low-gradient aortic stenosis (AS). ${ }^{2,3}$ Furthermore, PPM has subclinical effects that include persistence of LV overload and impaired recovery of coronary flow reserve, which in turn may hinder the regression of LV hypertrophy and dysfunction. ${ }^{2-4}$

Regression of LV hypertrophy after aortic valve replacement is an incompletely understood phenomenon. In a recent study, researchers at the University of Ottawa Heart Institute showed that either postoperative PPM or the presence of a baseline aortic regurgitation (AR) physiology can prolong the duration and limit the completeness of LV mass regression after aortic valve replacement. ${ }^{5}$ Transcatheter aortic valve replacement (TAVR) is now a widely accepted intervention for patients with severe AS who are deemed to have prohibitive or high surgical risk, and it is included as such in the American and European treatment guidelines. 6,7 Hemodynamic results with regard to the relief of AS with TAVR are excellent: for instance, studies have shown that TAVR performed on a small aortic annulus results in less PPM, likely as a result of a thinner stent frame and a tendency toward oversizing of TAVR prostheses relative to SAVR prostheses. ${ }^{8,9}$ Despite this favorable effect on PPM, however, long-term questions related to valve durability and persistent AR, which is found in a sizable proportion of patients who have undergone TAVR, are still incompletely answered.

In this edition of the Journal, Zorn and colleagues ${ }^{10}$ present their analysis of the incidence and prognosis of PPM in the TAVR and SAVR patient cohorts included in the

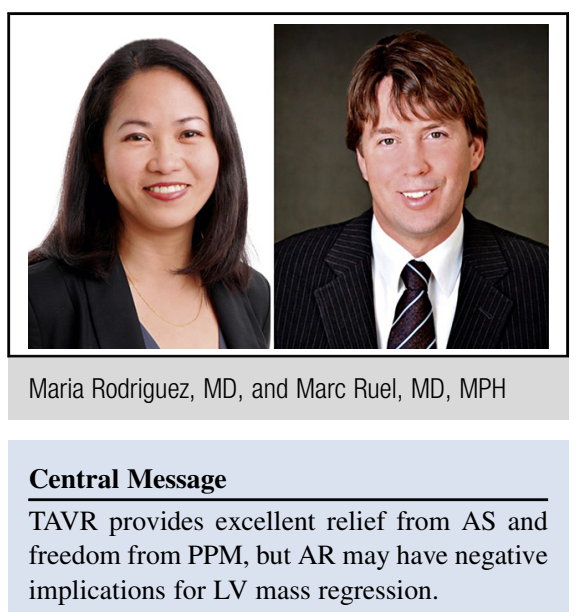

See Article page 1014.

CoreValve US High Risk Pivotal Trial. ${ }^{11}$ They showed that TAVR results in significantly lower incidence of severe PPM relative to SAVR $(7.0 \%$ vs $20.7 \%$ at 1 month, and $6.2 \%$ vs $25.7 \%$ at 1 year). Despite this difference in the incidence of severe PPM, there was no difference in mortality, however, and widespread improvement in heart failure functional class was observed regardless of PPM status. Only after Zorn and colleagues ${ }^{10}$ combined the populations of patients undergoing TAVR and SAVR did they observe that there was a higher mortality in the combined severe PPM subgroups; however, it is well-known that patients with PPM are generally sicker than patients who do not have PPM, and this study was no exception.

There remain 2 important questions highlighted by this clinical and echocardiographic study and another recent, similar subanalysis of the Sapien TAVR prosthesis in the Placement of Aortic Transcatheter Valve (PARTNER A) trial. ${ }^{12}$ First, was the impact of PPM after TAVR observed mostly in patients with LV dysfunction, as had been shown before in patients undergoing SAVR, , $3^{3}$ and was this interaction between PPM and LV dysfunction different between the TAVR and SAVR patient groups? Second, what was the impact of residual AR (more common with TAVR) on the inhibition of LV mass regression? In the study presented in this issue, Zorn and colleagues ${ }^{10}$ focused on AR of a least a moderate degree and found no effect; however, $46 \%$ of patients undergoing TAVR (vs $12 \%$ of those undergoing SAVR) had at least mild $A R$ at 1 month 
after aortic valve replacement, and the effects of mild AR were not examined. Furthermore, despite a higher incidence of PPM and generally higher transprosthetic gradients, SAVR was numerically superior to TAVR with regard to absolute LV mass regression by a factor of about 2 , as shown in the article's Supplemental Table 4. Thus, considering that residual AR is associated with mortality after TAVR, ${ }^{13,14}$ it is plausible that mild AR after TAVR is not completely innocuous and carries at least subclinical negative effects.

The evidence presented by Zorn and colleagues ${ }^{10}$ therefore, confirms that TAVR is a very good option for patients with severe aortic stenosis who would be at high risk if undergoing SAVR. One must note, however, that despite superior relief of AS with TAVR relative to SAVR in this trial population, the frequent occurrence of chronic mild AR in patients undergoing TAVR may have detrimental effects on LV mass regression. This postulated relationship warrants further study, especially as TAVR is being increasingly extended both to patients with LV dysfunction (in whom LV mass regression is particularly critical) and to patients with intermediate and low surgical risk, who would be expected to enjoy a long life and resolution of their LV hypertrophy after the relief of AS.

\section{References}

1. Pibarot P, Weissmann NJ, Stewart WJ, Hahn RT, Lindman BR, McAndrew T, et al. Incidence and sequelae of prosthesis-patient mismatch in transcatheter versus surgical valve replacement in high-risk patients with severe aortic stenosis: a PARTNER trial cohort A analysis. J Am Coll Cardiol. 2014;64:1323-34.

2. Ruel M, Al-Faleh H, Kulik A, Chan KL, Mesana TG, Burwash IG. Prosthesis-patient mismatch after aortic valve replacement predominantly affects patients with preexisting left ventricular dysfunction: effect on survival, freedom from heart failure, and left ventricular mass regression. J Thorac Cardiovasc Surg. 2006; 131:1036-44

3. Kulik A, Burwash IG, Kapila V, Mesana TG, Ruel M. Long-term outcomes after valve replacement for low gradient aortic stenosis: impact of prosthesis-patient mismatch. Circulation. 2006;114(1 Suppl):I553-8

4. Head S, Mokhles MM, Osnabrugge RL, Pibarot P, Mack MJ, Takkenberg JJ, et al. The impact of prosthesis-patient mismatch on long-term survival after aortic valve replacement: a systematic review and meta-analysis of 34 observationa studies comprising 27186 patients with 133141 patient-years. Eur Heart J. 2012;33:1518-29.

5. Une D, Mesana L, Chan V, Maklin M, Chan R, Masters RG, et al. Clinical impact of changes in left ventricular function after aortic valve replacement: analysis from 3112 patients. Circulation. 2015;132:741-7.

6. Nishimura RA, Otto CM, Bonow RO, Carabello BA, Erwin JP III, Guyton RA, et al; American College of Cardiology; American College of Cardiology/American Heart Association; American Heart Association. 2014 AHA/ACC guideline for the management of patients with valvular heart disease: a report of the American College of Cardiology/American Heart Association Task Force on Practice Guidelines. J Thorac Cardiovasc Surg. 2014;148:e1-132.

7. Vahanian A, Alfieri O, Andreotti F, Antunes MJ, Barón-Esquivias G, Baumgartner H, et al; ESC Committee for Practice Guidelines (CPG); Joint Task Force on the Management of Valvular Heart Disease of the European Society of Cardiology (ESC); European Association for Cardio-Thoracic Surgery (EACTS). Guidelines on the management of valvular heart disease (version 2012): the Joint Task Force on the Management of Valvular Heart Disease of the European Society of Cardiology (ESC) and the European Association for Cardio-Thoracic Surgery (EACTS). Eur J Cardiothorac Surg. 2012;42: S1-44.

8. Rodés-Cabau J, Pibarot P, Suri R, Kodali S, Thourani VH, Szeto WY, et al. Impact of aortic annulus size on valve hemodynamics and clinical outcomes after transcatheter and surgical aortic valve replacement: insights from the PARTNER Trial. Circ Cardiovasc Interv. 2014;7:701-11.

9. Clavel M, Webb JG, Pibarot P, Altwegg L, Dumont E, Thompson C, et al. Comparison of the hemodynamic performance of percutaneous and surgical bioprostheses for the treatment of severe aortic stenosis. J Am Coll Cardiol. 2009; 53:1883-91.

10. Zorn GL III, Little SH, Tadros P, Deeb GM, Gleason TG, Heiser J, et al. Prosthesis-patient mismatch in high-risk patients with severe aortic stenosis: A randomized trial of a self-expanding prosthesis. J Thorac Cardiovasc Surg. 2016; 151:1014-23.e3.

11. Adams DH, Popma JJ, Reardon MJ. Transcatheter aortic-valve replacement with a self-expanding prosthesis. N Engl J Med. 2014;371:967-8.

12. Hahn RT, Pibarot P, Stewart WJ, Weissman NJ, Gopalakrishnan D, Keane MG et al. Comparison of transcatheter and surgical aortic valve replacement in severe aortic stenosis: a longitudinal study of echocardiography parameters in cohort A of the PARTNER Trial. J Am Coll Cardiol. 2013;61:2514-21.

13. Kodali S, Pibarot P, Douglas PS, Williams M, Xu K, Thourani V, et al. Paravalvular regurgitation after transcatheter aortic valve replacement with the Edwards Sapien valve in the PARTNER trial: characterizing patients and impact on outcomes. Eur Heart J. 2015;36:449-56.

14. Mack MJ, Leon MB, Smith CR, Miller DC, Moses JW, Tuzcu EM, et al. 5-year outcomes of transcatheter aortic valve replacement or surgical aortic valve replacement for high surgical risk patients with aortic stenosis (PARTNER 1): a randomised controlled trial. Lancet. 2015;385:2477-84. 